\title{
Polypeptide Carrying a Periodic Arrangement of Naphthyl and p-Dimethylaminophenyl Groups. Two Chromophoric Arrays along a Single $\alpha$-Helical Polypeptide Chain
}

\author{
Yoshihito INAI, Masahiko SISIDO, ${ }^{*}+$ and Yukio IMANISHI \\ Department of Polymer Chemistry, and \\ * Research Center for Medical Polymers and Biomaterials, \\ Kyoto University, Sakyo-ku, Kyoto 606, Japan
}

(Received October 4, 1989)

\begin{abstract}
A sequential polypeptide with a repeating unit of [dmaPhe-Glu(OMe)-napAla$\mathrm{Glu}(\mathrm{OBzl})$ ] was synthesized [dmaPhe $=\mathrm{L}-p$-dimethylaminophenylalanine $(\mathrm{D})$, napAla $=\mathrm{L}-1$-naphthylalanine $(\mathrm{N})$, Glu $(\mathrm{OMe})=\gamma$-methyl L-glutamate $(\mathrm{G})$, Glu $(\mathrm{OBzl})=\gamma$-benzyl L-glutamate $(\mathrm{G})]$. CD spectrum in HFIP/TMP mixed solvent indicated a right-handed $\alpha$-helical main chain. The spatial arrangement of the chromophores was predicted from an empirical conformational energy calculation. The interchromophore distance between naphthyl and the nearest dimethylaminophenyl group was $12 \AA$. Fluorescence spectrum of the polypeptide consisted of the monomer fluorescences of the D group and a very small amount of the exciplex emission. No electron-transfer quenching was observed. The fluorescence behavior is consistent with the predicted arrangement of the chromophores.

KEY WORDS Polypeptide / Conformation / Chromophore / Fluorescence / Exciplex /
\end{abstract}

Helical polypeptide provides a rigid framework on which different types of chromophores can be arranged in a specific order with different spacings. ${ }^{1,2}$ In the previous study, ${ }^{3}$ a sequential polypeptide with the repeating unit of [dmaPhe-napAla-Glu(OBzl)], poly(DNG) $(\mathbf{I}, m=0)$, was synthesized [dmaPhe $=\mathrm{L}$ - $p$-dimethylaminophenylalanine $(\mathrm{D})$, napAla $=\mathrm{L}-1-$ naphthylalanine $(\mathrm{N}), \mathrm{Glu}(\mathrm{OBzl})=\gamma$ - benzyl L-glutamate $(G)$ ]. Conformational analysis predicted that the nearest pair of $D$ and $\mathrm{N}$ in poly(DNG) is separated by $6.1 \AA$ (center-to-center). The fluorescence spectrum consisted mostly of exciplex emission with a quantum yield of $0.025\left(\lambda_{\mathrm{ex}}=285 \mathrm{~nm}\right)$ with very small emissions from the monomer excited states of $\mathrm{D}$ and $\mathrm{N}$ groups. The spectral behavior indicates that a large part of the excited state

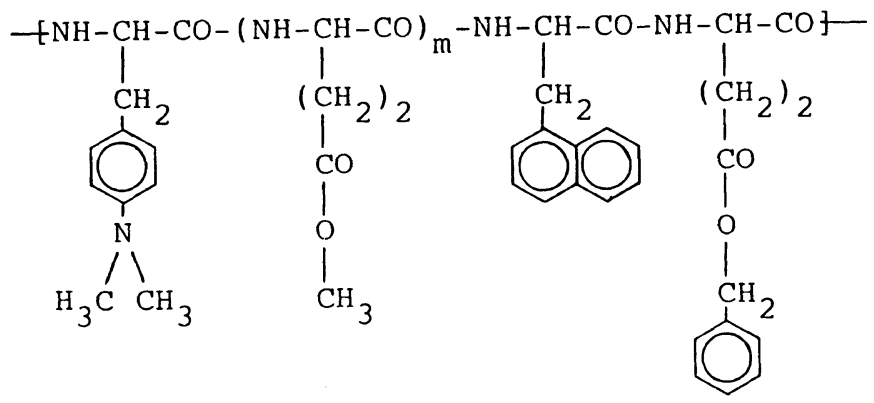

(I)

$$
m=0: \operatorname{poly}(\mathrm{DNG})
$$$$
m=1: \operatorname{poly}(\mathrm{DGNG})
$$

+ To whom correspondence should be addressed: Research Laboratory of Resources Utilization, Tokyo Institute of Technology, 4259 Nagatsuta, Midori-ku, Yokohama 227, Japan. 
of $\mathrm{D}(\mathrm{N})$ group is quenched by the $\mathrm{N}(\mathrm{D})$ group by an electron transfer from $D^{*}$ to $\mathrm{N}$ or from D to $\mathrm{N}^{*}$. A small part of the encounter complex formed by the electron transfer leads to exciplex formation.

In order to examine the dependence of the excited-state interactions of $\mathrm{D}$ and $\mathrm{N}$ groups on their distances from each other, a different sequential polypeptide carruing dmaPhe and napAla units in a different repeating unit, poly(DGNG) $(\mathbf{I}, m=1)$, was synthesized.

As will be shown later, since the $\mathrm{D}-\mathrm{N}$ pair of poly(DGNG) is more separated than the D-N pair of poly(DNG), different electronic interactions in the excited state may be expected for the two polypeptides.

A tripeptide, Boc-dmaPhe-Glu(OMe)-nap-
Ala-OBzl (BDGNBz, II) synthesized as an intermediate for poly(DGNG) was used as a low-molecular weight model compound having the same $\mathrm{D}-\mathrm{G}-\mathrm{N}$ sequence.

As the low-molecular weight model compounds containing single napAla or dmaPhe unit, Boc-Glu(OMe)-napAla-Glu(OMe $)_{2}$ OBzl $\left(\mathrm{BGNG}_{2} \mathrm{Bz}\right.$, III) and Boc-Glu(OMe)dmaPhe-Glu(OMe $)_{3}-\mathrm{OMe} \quad\left(\mathrm{BGDG}_{3} \mathrm{M}, \quad\right.$ IV $)$ were used.

\section{EXPERIMENTAL}

\section{Materials}

Poly(DGNG) was prepared by a polycondensation of the activated ester of the corresponding tetrapeptide. The tetrapeptide<smiles>CCOC(=O)C(CCC(=O)NC(Cc1cccc2ccccc12)C(=O)OOCc1ccccc1)NC(=O)C(Cc1ccc(N(C)C)cc1)NC(=O)OC</smiles><smiles>CCCC(NC(=O)C(Cc1cccc2ccccc12)NC(=O)C(CCC(=O)OCc1ccccc1)NC(=O)OCC(C)(C)C)C(=O)OCc1ccccc1</smiles>

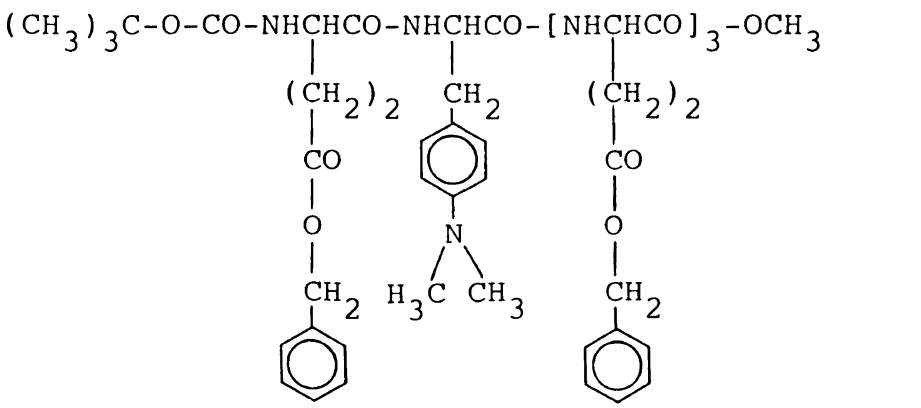


was synthesized by a conventional liquidphase method. The synthesis and optical resolution of L-1-naphthylalanine ${ }^{4}$ and L-p-dimethylaminophenylalanine $e^{3,5}$ have been reported. The following abbreviations are used: Boc $=t$-butyloxycarbonyl; OBzl $=$ benzyl ester; $\mathrm{OSu}=\mathrm{N}$-hydroxysuccinimide ester; $\mathrm{DCHA}=$ dicyclohexylamine; $\mathrm{Tos} \mathrm{OH}=p$-toluenesulfonic acid; WSC =1-ethyl-3-(3-dimethylaminopropyl)carbodiimide hydrochloride (watersoluble carbodiimide); $\mathrm{HOBt}=1$-hydroxybenzotriazole; $\mathrm{TEA}=$ triethylamine; $\mathrm{DMF}=$ dimethylformamide; THF = tetrahydrofuran.

\section{Boc-Glu(OMe)-nap Ala-OBzl}

Boc-Glu(OMe)-OH DCHA salt (Kokusan Chemical, Tokyo) was suspended in ethyl acetate and washed with $5 \% \mathrm{KHSO}_{4}$ to remove the DCHA. The ethyl acetate solution was washed with $10 \% \mathrm{NaCl}$ solution and dried over $\mathrm{MgSO}_{4}$. The solvent was evaporated to obtain Boc-Glu(OMe). The latter $(0.47 \mathrm{~g}, 1.8 \mathrm{mmol})$ and napAla-OBzl TosOH salt $(0.75 \mathrm{~g}, 1.6$ $\mathrm{mmol})$ was dissolved in DMF $(10 \mathrm{ml})$ and WSC $(0.33 \mathrm{~g}, 1.7 \mathrm{mmol})$, HOBt $(0.23 \mathrm{~g}, 1.7$ $\mathrm{mmol})$, and TEA $(0.22 \mathrm{ml}, 1.7 \mathrm{mmol})$ were added at $0^{\circ} \mathrm{C}$ and stirred for $3 \mathrm{~h}$ at ice temperature. Stirring was continued for further 1 day at room temperature. The solvent was evaporated and the residue was redissolvd in ethyl acetate. The solution was washed with $10 \%$ citric acid, saturated $\mathrm{NaCl}, 3 \% \mathrm{NaHCO}_{3}$, and saturated $\mathrm{NaCl}$ solutions and dried over $\mathrm{MgSO}_{4}$. Evaporation of the solvent and recrystallization from ethyl acetate/hexane mixture gave white solids. Yield $0.78 \mathrm{~g}(89 \%)$. mp $108-110^{\circ} \mathrm{C}$.

\section{Boc-dmaPhe-Glu(OMe)-napAla-OBzl (BD- $G N B z$ )}

The Boc group of Boc-Glu(OMe)-napAlaOBzl $(0.5 \mathrm{~g}, 0.91 \mathrm{mmol})$ was removed by dissolving it in $4 \mathrm{~N} \mathrm{HCl} /$ dioxane $(10 \mathrm{ml})$ for $60 \mathrm{~min}$. The dioxane was evaporated and the oil was washed with ether and dried under vacuum. The dipeptide hydrochloride was dissolved in DMF and Boc-dmaPhe $(0.323 \mathrm{~g}$, $1.0 \mathrm{mmol}$ ) was added. Under cooling with ice, WSC $(0.192 \mathrm{~g}, 1.0 \mathrm{mmol})$, HOBt $(0.135 \mathrm{~g}$, $1.0 \mathrm{mmol})$, and TEA $(0.12 \mathrm{ml})$ were added to the DMF solution. The mixture was stirred for $3 \mathrm{~h}$ at $0^{\circ} \mathrm{C}$ and the stirring was continued for further 1 day at room temperature. The reaction mixture was treated in the same manner as above. the crude compound obtained was chromatographed with a silica gel/ethyl acetate column. Yield $0.44 \mathrm{~g}(66 \%), \mathrm{mp} 163$ $164 \mathrm{C}$. Anal. Calcd for $\mathrm{C}_{42} \mathrm{H}_{50} \mathrm{~N}_{4} \mathrm{O}_{8}: \mathrm{C}$, $68.27 \%$;, $6.82 \%$; N, $7.58 \%$. Found: C, $68.44 \%$; H, 6.92\%; N, 7.50\%.

\section{Boc-dmaPhe-Glu(OMe)-napAla-OH}

Boc-dmaPhe-Glu(OMe)-napAla-OBzl $(0.2 \mathrm{~g})$ was dissolved in ethanol $(30 \mathrm{ml})$ and $5 \%$-palladium carbon $(0.1 \mathrm{~g})$ was added. The mixture was stirred under hydrogen atmosphere for $4 \mathrm{~h}$ at room temperature. The catalyst was filtered off and the solvent was evaporated. The remaining solid was recrystallized from ethyl acetate/hexane. Yield $0.125 \mathrm{~g}$ $(67 \%) . \mathrm{mp} 102-108^{\circ} \mathrm{C}$.

\section{Boc-dmaPhe-Glu(OMe)-nap Ala-Glu(OBzl)- $\mathrm{OSu}$}

The free acid obtained above $(0.125 \mathrm{~g}, 0.19$ $\mathrm{mmol})$ was dissolved in anhydrous THF $(2 \mathrm{ml})$ and cooled to $-10--15^{\circ} \mathrm{C}$. $N$-Methylmorpholine $(21.6 \mu \mathrm{l})$ and isobutyl chloroformate $(25.8 \mu \mathrm{l})$ were added and the mixture was stirred at $-10^{\circ} \mathrm{C}$. After $5 \mathrm{~min}$, Glu(OBzl)OSu $\mathrm{HCl}$ salt $(0.075 \mathrm{~g})$ in DMF and $N$-methylmorpholine $(22.6 \mu \mathrm{l})$ were added and the mixture was stirred for $1 \mathrm{~h}$ at $-10--15^{\circ} \mathrm{C}$. The mixture was left standing for $12 \mathrm{~h}$ at $0^{\circ} \mathrm{C}$ and diluted with ethyl acetate $(100 \mathrm{ml})$. The solution was washed with saturated $\mathrm{NaCl}$ solution and dried over $\mathrm{MgSO}_{4}$. The active ester was further purified by being passed through a silica gel/ethyl acetate column. Yield $22 \mathrm{mg}(12 \%)$. mp $146-149^{\circ} \mathrm{C}$. Anal. Calcd for $\mathrm{C}_{51} \mathrm{H}_{60} \mathrm{~N}_{6} \mathrm{O}_{13}: \mathrm{C}, 63.47 \% ; \mathrm{H}, 6.27 \% ; \mathrm{N}$, $8.71 \%$. Found: C, $63.60 \%$;, $6.54 \%$; 
$8.43 \%$

\section{$\operatorname{Poly}(D G N G)$}

The activated ester of the $N$-protected tetrapeptide was dissolved in $4 \mathrm{~N} \mathrm{HCl} /$ dioxane. After $1 \mathrm{~h}$, the solvent was evaporated and the remaining residue was washed with ether to obtain dmaPhe-Glu(OMe)-napAla-Glu(OBzl)-OSu $\cdot 2 \mathrm{HCl}$. The latter was dissolved in DMF and 1.5-fold molar excess of TFA was added and stored at room temperature. After 2 days, 1 mol of TEA was further added and the mixture was stored for 3 days. The polypeptide was precipitated with methanol and the precipitate was washed with $3 \% \mathrm{NaHCO}_{3}$, water, methanol, and ether. The polypeptide was subjected to gel chromatography (Sephadex LH-60/DMF) and the fraction eluted at the limiting molecular weight of LH-60 (MW > $10^{4}$ ) was collected.

\section{MEASUREMENTS}

Since poly(DGNG) was not soluble in any single organic solvent that is transparent down to $190 \mathrm{~nm}$, a mixed solvent of hexafluoroisopropanol (HFIP) and trimethyl phosphate (TMP) was used for spectroscopic measurements. For absorption and CD spectra, an HFIP/TMP $(10: 90, v / v)$ mixture was used. For fluorescence measurements, a mixture of $3: 97,(\mathrm{v} / \mathrm{v})$ was used. Qualitatively, the absorption and fluorescence spectra of model peptides and poly(DGNG) were not sensitive to the content of HFIP. For fluorescence spectroscopy, the sample solution was bubbled with nitrogen gas for $20 \mathrm{~min}$ before measurement. Spectroscopic data were recorded on the following instruments: absorption, Hitachi 200-20; fluorescence, Hitachi MPF-4; CD, Jasco J-20.

\section{RESULTS AND DISCUSSION}

\section{Circular Dichroism}

Figure 1 compares circular dichroic (CD) spectra of poly(DGNG) and poly[Lys(Z)-Lys-

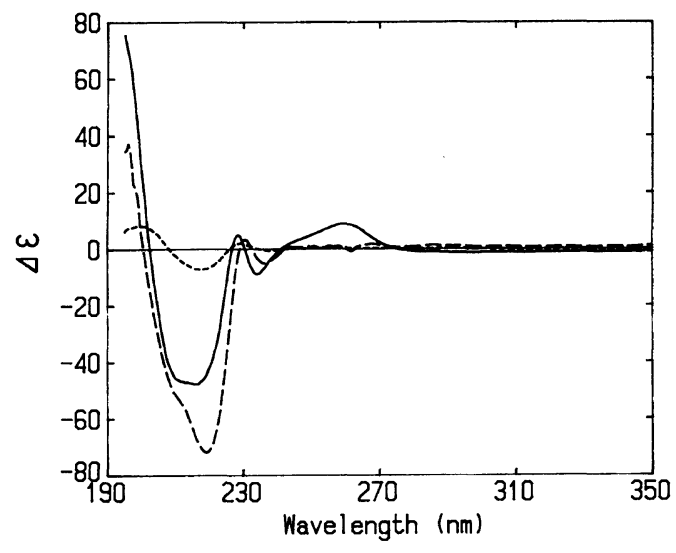

Figure 1. CD spectra of poly(DGNG) $(-)([\mathrm{nap}]=$ $6 \times 10^{-5} \mathrm{M}$, in HFIP/TMP $\left.(10: 90)\right)$, poly $\left(\mathrm{L}_{3} \mathrm{~N}\right)(---)$ ([nap] $=4 \times 10^{-5} \mathrm{M}$, in HFIP/TMP $\left.(10: 90)\right)$, and BDGNBz (----) $\left([\mathrm{nap}]=6 \times 10^{-5} \mathrm{M}\right.$, in HFIP/TMP $(10: 90))$.

(Z)-Lys(Z)-napAla] $\left[\operatorname{poly}\left(\mathrm{L}_{3} \mathrm{~N}\right)\right]^{6}$ in $\mathrm{HFIP} /$ TMP (10:90) mixture. Both poly $\left(\mathrm{L}_{3} \mathrm{~N}\right)$ and poly(DGNG) contain a napAla unit in every four amino acid units. The CD spectra of the amide and naphthyl absorption regions $(195-240 \mathrm{~nm})$ of the two sequential polypeptides are very similar to each other. Since conformation of poly $\left(\mathrm{L}_{3} \mathrm{~N}\right)$ has been assigned to a right-handed $\alpha$-helix, the resemblance suggests the $\alpha$-helical main-chain conformation of poly(DGNG). The resemblance of the $\mathrm{CD}$ patterns at the naphthyl ${ }^{1} \mathrm{Bb}$ band around $230 \mathrm{~nm}$ also suggests similar orientations of naphthyl groups along the $\alpha$-helical main chain in the two polypeptides. The positive $C D$ at the absorption band of $D$ group around $260 \mathrm{~nm}$ suggests a regular or, at least, resticted orientation of $\mathrm{D}$ groups along the helix.

In the same figure, $C D$ spectrum of $\mathrm{BDGNBz}$ is also shown. The CD intensity is much smaller than that of poly(DGNG), suggesting the importance of the helical main chain to induce strong $\mathrm{CD}$ signals from $\mathrm{D}$ and $\mathrm{N}$ groups. 


\section{CONFORMATIONAL ANALYSIS}

The results of $\mathrm{CD}$ spectroscopy indicated that the main chain of poly(DGNG) is a righthanded $\alpha$-helix and the orientation of the sidechain chromophores are restricted. A conformational energy calculation based on the ECEPP system ${ }^{7}$ was carried out to predict stable orientations of the side chains of poly(DGNG). Structural and energy parameters for $\mathrm{D}$ and $\mathrm{N}$ groups have been described previously. ${ }^{3}$ In the calculation, the $\mathrm{Glu}(\mathrm{OMe})$ and $\mathrm{Glu}(\mathrm{OBzl})$ units were replaced by alanine units for simplicity. This simplification may be justified by the fact that the sequential polypeptide having the repeating unit of [dmaPheAla-napAla-Glu(OBzl)] showed similar CD pattern to that of poly(DGNG). ${ }^{8}$

The energy contour map for the orientation of naphthyl group in Ac-Ala ${ }_{4}$-napAla-Ala ${ }_{4}^{-}$ NMA $(\mathrm{Ac}=$ acetyl; $\mathrm{NMA}=N$-methylamide) with $\alpha$-helical main chain, has been calculated. ${ }^{3}$ The minimum-energy orientation is $\left(\chi_{1}\right.$, $\left.\chi_{2}\right)=\left(190^{\circ}, 260^{\circ}\right)$. Similarly the most stable orientation of dimethylaminophenyl group in an $\alpha$-helical Ac-Ala -dmaPhe-Ala $_{4}$-NMA was $\left(190^{\circ}, 270^{\circ}\right){ }^{3}$ Starting from the stable orientations for the two side groups, energy minimi- zation of the side-chain conformation of poly(dmaPhe-Ala-napAla-Ala $) \quad(n=8)$ was performed.

During the calculation, the polypeptide main chain was fixed to a right-handed $\alpha$ helical conformation $\left(\phi=-57^{\circ}, \psi=-47^{\circ}\right)$. Furthermore, a helical symmetry for the side chain orientations was assumed; i.e., the same $\chi_{1}{ }^{\mathrm{D}}$ and $\chi_{2}{ }^{\mathrm{D}}$ values were assumed for each dmaPhe unit and the same $\chi_{1}{ }^{\mathrm{N}}$ and $\chi_{2}{ }^{\mathrm{N}}$ values for each napAla unit.

The minimum-energy conformation obtained is shown in Figure 2. ${ }^{9}$ In the conformation, the center-to-center distance between the nearest $\mathrm{D}-\mathrm{N}$ pair is $11.6 \AA$, whereas the distance between the nearest $\mathrm{N}-\mathrm{N}$ pair is $7.2 \AA$ and that between the nearest $D-D$ pair is $7.1 \AA$. The interchromophore distances are schematically shown in Figure 3, along with those for poly(DNG). It is evident that the nearest $\mathrm{D}-\mathrm{N}$ distance is shorter in poly(DNG) (6.1 $\AA)$ than in poly(DGNG) (11.6 $)$. The different $\mathrm{D}-\mathrm{N}$ distance essentially determines the photophysical behavior of the two polypeptides.

The energy contour maps for the naphthyl side group indicate that the range of thermal flucturation is very small $\left(\chi_{1}=190 \pm 15^{\circ} ; \chi_{2}=\right.$

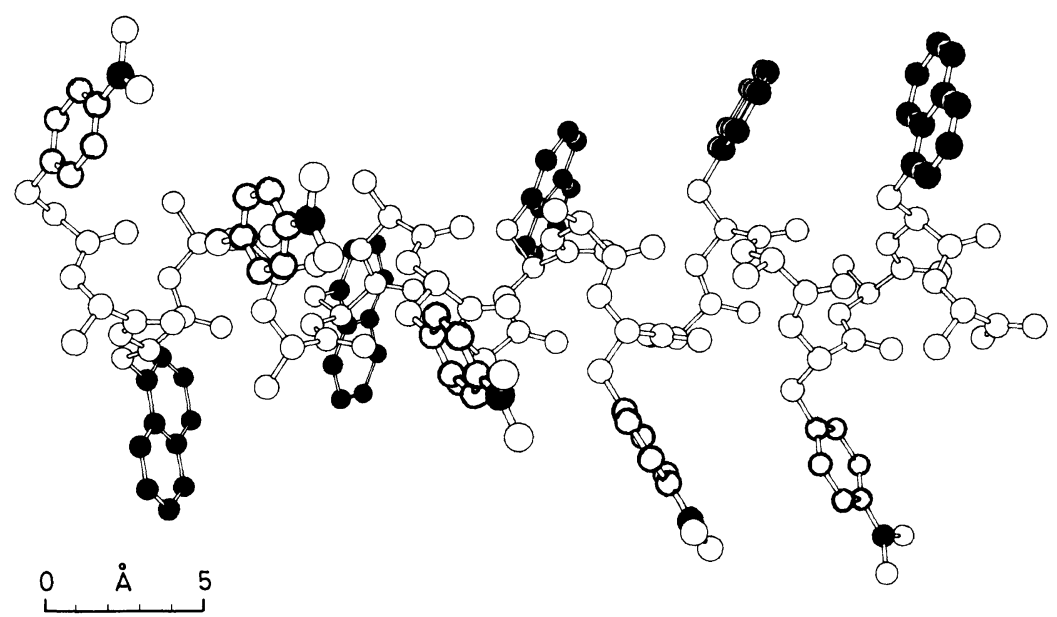

Figure 2. The most probable conformation of poly(DGNG). The main chain conformation is $\alpha$-helix $\left(\phi=-57^{\circ} ; \psi=-47^{\circ} ; \omega=180^{\circ}\right)$. The energy minimization was performed on the side-chain orientation, $\left(\chi_{1}, \chi_{2}\right)=\left(185^{\circ}, 268^{\circ}\right)$ for dmaPhe unit and $\left(188^{\circ}, 257^{\circ}\right)$ for napAla unit. 


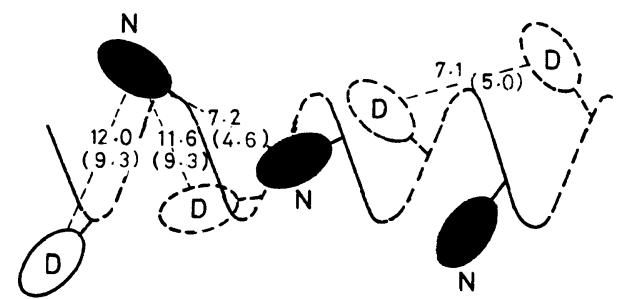

(a) poly(DGNG)

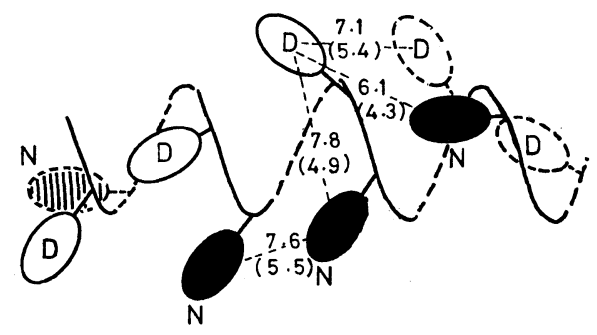

(b) $\operatorname{poly}(D N G)$

Figure 3. The center-to-center (edge-to-edge) interchromophore distances for the most probable conformations of poly(DGNG) (a) and poly(DNG) (b).

$260 \pm 5^{\circ}$ ), provided that the main chain is rigidly fixed in an $\alpha$-helical conformation. On the other hand, the fluctuation of $D$ group is predicted to be fairly large $\left(\chi_{1}=190 \pm 15^{\circ} ; \chi_{2}=\right.$ $\left.270 \pm 30^{\circ}\right)$. But only one stable orientation was found in the energy contour map. As shown by the CD spectrum, the orientation of D goup is also restricted. The rotation of $\mathrm{D}$ group, if it actually occurs, may not be very important to the spectroscopic behavior of poly(DGNG), since, as can be understood from the molecular model (Figure 2), the rotation will not change the interchromophore distance between the D and $\mathrm{N}$ groups significantly.

\section{ABSORPTION SPECTRA}

Figure 4 shows absorption spectra of poly(DGNG) and BDGNBz in HFIP/TMP (10:90) mixed solvent. These spectra are compared with the sum of the absorption spectra of the model peptides containing napAla (III) and dmaPhe (IV) units, respectively. The

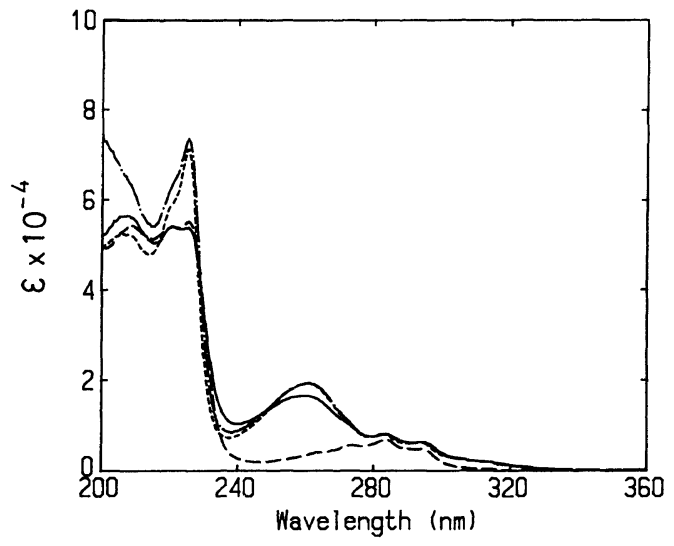

Figure 4. Absorption spectra of poly(DGNG) (-), poly $\left(\mathrm{L}_{3} \mathrm{~N}\right)(---), \mathrm{BDGNBz}(----)$, and the sum of the spectra of $\mathrm{BGNG}_{2} \mathrm{Bz}$ and $\mathrm{BGDG}_{3} \mathrm{M}(-\cdot-)$. The solvent is pure TMP for poly $\left(\mathrm{L}_{3} \mathrm{~N}\right)$ and HFIP/TMP $(10: 90)$ for other samples. Room temperature. [nap]= $2 \times 10^{-5} \mathrm{M}$.

spectrum of BDGNBz was virtually the same as that of the sum spectrum, indicating the absence of ground-state interactions between $\mathrm{D}$ and $\mathrm{N}$ groups in the tipeptide. The spectrum of poly(DGNG) at longer wavelengths than $280 \mathrm{~nm}$ is also indistinguishable from the sum spectrum, indicating the absence of groundstate dimer or aggregates in the polypeptide. The absorption of D group around $260 \mathrm{~nm}$ is smaller than the sum spectrum and spectrum of the tripeptide. The hypochromic effect may be related to the $C D$ of moderate intensity at the absorption band and is interpreted in terms of weak dipole-dipole interactions between neighboring D groups and, possibly, between $\mathrm{D}$ and $\mathrm{N}$ groups along the helix. The naphthyl ${ }^{1} \mathrm{Bb}$ band (around $225 \mathrm{~nm}$ ) of poly(DGNG) shows a stronger hypochromism. Indicating, again, an excitonic state for $\mathrm{N}$ groups caused by dipole-dipole interactions. $\operatorname{Poly}\left(\mathrm{L}_{3} \mathrm{~N}\right)$ also shows the hypochromism at the naphthyl ${ }^{1} \mathrm{Bb}$ band with the same molar absorption coefficient. This, again, supports the same spatial arrangement of $\mathrm{N}$ groups in the two sequential polypeptides. 


\section{PHOTOPHYSICAL PROCESSES PREDICTED FROM THE CHROMOPHORE ARRANGEMENT}

Before discussing the photophysical behavior of poly(DGNG), several aspects that are expected from the molecular structure and from the absorption spectrum should be considered. First, since the absorption spectra of $\mathrm{D}$ and $\mathrm{N}$ groups largely overlap, neither the $\mathrm{D}$ group nor $\mathrm{N}$ group can be photoexcited separately. However, the relative absorbance of these groups is different, depending on the excitation wavelength. For example, at $265 \mathrm{~nm}$ $73 \%$ of photoenergy is absorbed by the D group, whereas at $285 \mathrm{~nm} 83 \%$ is absorbed by the $\mathrm{N}$ group in poly(DGNG). Therefore, the fluorescence spectrum will become dependent on the excitation wavelength.

The photoenergy absorbed by one of the D or $\mathrm{N}$ groups will not stay on the same chromophore. Energy transfers are energetically possible in all four directions, i.e., $\mathrm{N}^{*} \rightarrow \mathrm{N}$, $\mathrm{N}^{*} \rightarrow \mathrm{D}, \mathrm{D}^{*} \rightarrow \mathrm{N}$, and $\mathrm{D}^{*} \rightarrow \mathrm{D}$. According to the Förster's theory, the rate of energy transfer is calculated by the equation $k=\tau_{0}{ }^{-1}\left(r_{0} / r\right)^{6}$, where $\tau_{0}$ is the intrinsic lifetime of the excited state of the energy donor and $r_{0}$ is the critical distance for the energy transfer which was estimated to be: $8.8\left(\mathrm{~N}^{*} \rightarrow \mathrm{N}\right), 13.8\left(\mathrm{~N}^{*} \rightarrow \mathrm{D}\right)$, $5.6\left(\mathrm{D}^{*} \rightarrow \mathrm{N}\right)$, and $8.7\left(\mathrm{D}^{*} \rightarrow \mathrm{D}\right) \AA . .^{10}$ The intrinsic lifetimes of the $\mathrm{D}$ and $\mathrm{N}$ groups were measured on the corresponding model peptide, IV (3.8 ns) and III (59 ns), ${ }^{11}$ respectively. Using the center-to-center interchromophore distances listed in Figure 3, the rate constants of energy transfer were calculated to be: $k=$ $5.7 \times 10^{7}\left(\mathrm{~N}^{*} \rightarrow \mathrm{N}\right), 4.8 \times 10^{7}\left(\mathrm{~N}^{*} \rightarrow \mathrm{D}\right), 3.3 \times$ $10^{6}\left(\mathrm{D}^{*} \rightarrow \mathrm{N}\right)$, and $8.2 \times 10^{8}\left(\mathrm{D}^{*} \rightarrow \mathrm{D}\right)\left(\mathrm{s}^{-1}\right) .{ }^{12}$ These rate constants should be compared with the rate constants of the decay of noninteracting $\mathrm{D}$ and $\mathrm{N}$ groups, which are given as the inverse of the intrinsic lifetimes described above: $2.6 \times 10^{8}$ and $1.7 \times 10^{7} \mathrm{~s}^{-1}$, for $\mathrm{D}$ and $\mathrm{N}$ groups, respectively. The rate constant of $\mathrm{N}^{*} \rightarrow \mathrm{N}$ energy transfer is faster than the decay rate of $\mathrm{N}^{*}$ and the rate constant of $\mathrm{D}^{*} \rightarrow \mathrm{D}$ energy transfer is much faster than the decay rate of $\mathrm{D}^{*}$. The energy transfer from $\mathrm{N}^{*}$ to $\mathrm{D}$ may occur within the lifetime of the $\mathrm{N}^{*}$ state but that from $\mathrm{D}^{*}$ to $\mathrm{N}$ is unlikely to occur within the lifetime of $\mathrm{D}^{*}$. When the $\mathrm{D}$ group is excited, the photoenergy may migrate along the one-dimensional array of D groups, but the energy transfer to the $\mathrm{N}$ group is unlikely. The photoenergy absorbed by the $\mathrm{N}$ group may also migrate along the one-dimensional array of $\mathrm{N}$ groups. The energy migration along the array of $\mathrm{N}$ groups on poly $\left(\mathrm{L}_{3} \mathrm{~N}\right)$ has been experimentally observed. ${ }^{2}$ However, the above prediction indicates that the migration along the $\mathrm{N}$ groups is much slower than that along the array of $\mathrm{D}$ groups. The energy migration rate along the $\mathrm{N}$ groups is comparable to the rate of energy transfer from $N^{*}$ to $\mathrm{D}$. Therefore, evaluation of the energy transfer rates predicts that the energy absorbed in one of the D groups will migrate along the array of $\mathrm{D}$ groups, whereas the energy absorbed in one of the $\mathbf{N}$ groups will migrate locally along the array of $\mathrm{N}$ groups and will be transferred to the $\mathrm{D}$ group with high efficiency.

Electron transfer from $\mathrm{D}^{*}$ to $\mathrm{N}$ or from $\mathrm{D}$ to $\mathrm{N}^{*}$ is possible. Also exciplex formation is possible in the excited $\mathrm{D}-\mathrm{N}$ pair. However, as seen from Figure 3, the nearest distance between $\mathrm{D}$ and $\mathrm{N}$ groups in poly(DGNG) seems too long for these electron-transfer-type interactions to occur.

In a separate study, a polypeptide carrying a single pair of $\mathrm{D}$ and $\mathrm{N}$ groups on an $\alpha$-helical polypeptide (V) was synthesized. ${ }^{13}$

The distance and relative orientation of the $\mathrm{D}-\mathrm{N}$ pair are expected to be the same as those of the nearest pair in poly(DGNG). A detailed analysis of the fluorescence spectra of $\mathbf{V}$ indicated that the energy transfer from $\mathrm{N}^{*}$ to D occcurs, whereas that from $D^{*}$ to $N$ does not. This is consistent with the above prediction. When only the $\mathrm{D}$ group was photoexcited in $\mathrm{V}$, the fluorescence quantum yield of $\mathrm{D}$ was about the same as that of the isolated D 


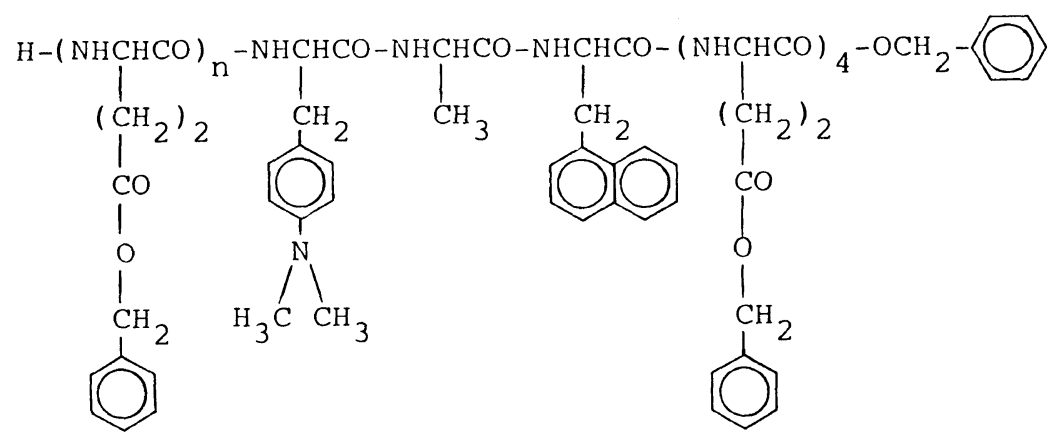

group in poly( $\gamma$-benzyl L-glutamate). Thus the electron transfer or the exciplex formation is absent in the excited state of the $\mathrm{D}-\mathrm{N}$ pair separated by about $12 \AA .^{13}$

Taking the above consideration and the experimental results into account, a picture for the photoelectronic property of poly(DGNG) can be drawn as follows: Poly(DGNG) holds chromophoric arrays of $\mathrm{D}$ and $\mathrm{N}$ groups and the energy transfer from $D^{*}$ to $N$ and the electron-transfer-type interactions are very unlikely. Since energy transfer from $N^{*}$ to $D$ is possible, the energy absorbed by the $\mathrm{N}$ group will ultimately be transferred to the $\mathrm{D}$ group.

The above consideration assumes a perfect helical structure of poly(DGNG) as shown in Figures 2 and 3. Actually, the number of dmaPhe-Glu(OMe)-napAla-Glu(OBzl) units may be of the order of 10 . The terminal portions of the helix may be more or less unfolded and thermal fluctuation cannot be ignored. ${ }^{14}$ The presence of a small amount of D-isomer may cause a configurational defect that may produce a site where electron transfer or exciplex formation occurs. It should thus be of interest to examine the adequacy above consideration.

\section{FLUORESCENCE SPECTRA AND TEMPERATURE DEPENDENCE}

The fluorescence spectra of poly(DGNG), poly(DNG), and BDGNBz are shown in Figure 5. The excitation wavelength was $265 \mathrm{~nm}$, at which $73 \%$ of photoenergy was

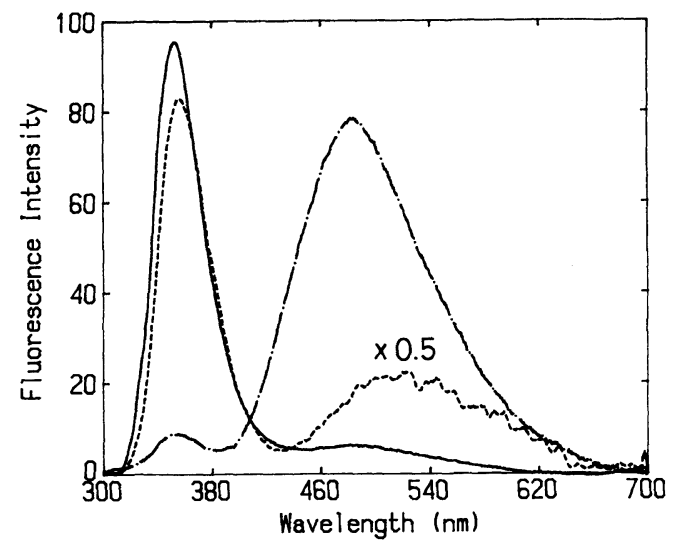

Figure 5. Fluorescence spectra of poly(DGNG) $(-)$, poly(DNG) (-•-), and BDGNBz (---, scale $\times 0.5)$ in $\mathrm{HFIP} / \mathrm{TMP}(3: 97)$ at room temperature. [nap] $=1 \times 10^{-5} \mathrm{M}, \lambda_{\mathrm{ex}}=265 \mathrm{~nm}$.

absorbed by $\mathrm{D}$ group, in the case of poly(DGNG). The monomer fluorescence of $\mathrm{D}$ group is predominant in poly(DGNG), whereas exciplex emission dominates in poly(DNG). It is evident that the spatial arrangement of $\mathrm{D}$ and $\mathrm{N}$ groups in poly(DNG) is very favorable for exciplex formation, whereas that of poly(DGNG) is very unfavorable. Therefore, the importance of the chromophoric arrangement to control the photophysical process is demonstrated. The importance of the fixed arrangement of chromophores is also evident from the fluorescence spectrum of the tripeptide II, which have the same sequence of amino acid units, dmaPhe-Glu(OMe)-napAla. The latter shows a much stronger exciplex emission than poly(DGNG). 
As will be shown below, the exciplex of the tripeptide is formed by thermal molecular motions that are active in the small peptide.

The monomer fluorescence of poly(DGNG) includes no contribution from that of the $\mathrm{N}$ group. This is reasonable, since the energy absorbed by the $\mathrm{N}$ group, which should amount to $27 \%$ of the total energy, may be transferred to the D group, whereas the inverse energy transfer is unlikely. Incidentally, the fluorescence spectra of poly(DGNG) when excited at $285 \mathrm{~nm}$ with $83 \%$ of photoenergy initially absorbed by $\mathrm{N}$ group, showed an $\mathrm{N}$ fluorescence of a marginal intensity. This indicates the energy transfer from $N^{*}$ to $D$ is highly efficient in poly(DGNG).

The quantum yield of the monomer fluorescence of the $\mathrm{D}$ group based on the total $(\mathrm{N}+\mathrm{D})$ absorbance at $265 \mathrm{~nm}$ is 0.021 for poly(DGNG). The quantum yield based on the absorbance of D group at $265 \mathrm{~nm}$ is 0.029 . Assuming that $84 \%$ of photoenergy initially absorbed by $\mathrm{N}$ group is transferred to $\mathrm{D},{ }^{14}$ the quantum yield based on the effective amount of the excited D group should be 0.022 . This value is close to the value $(0.0255)$ for the polypeptide containing a single dmaPhe unit, $\mathrm{Glu}(\mathrm{OBzl})_{n}$-dmaPhe-Glu(OBzl $)_{4}$-OBzl . Similar quantum yields showed that quenching processes other than the exciplex formation are not important in poly(DGNG). The very little exciplex emission and absence of quenching process indicate that the above picture for the photophysical processes predicted from the spatial arrangement of the chromophores holds in this polypeptide, except for the small exciplex emission.

To investigate the nature of the exciplex, the temperature dependence of the exciplex/ monomer (D) intensity ratios of poly(DGNG), poly(DNG), and BDGNBz were measured over the temperature range of $-60^{\circ}-+20^{\circ}$, and are shown as an Arrhenius-type plot in Figure 6 . The intensity ratio of poly(DGNG) is almost independent of temperature, whereas that of BDGNBz decreases sharply with

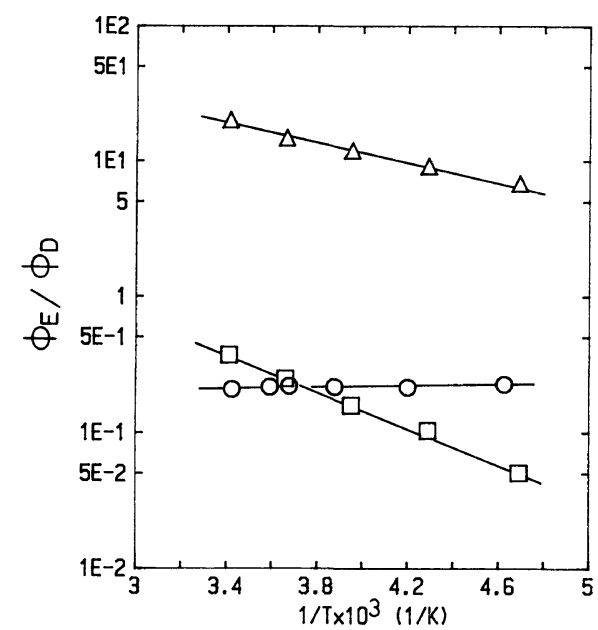

Figure 6. Arrhenius-type plot of the exciplex/(monomer fluorescence of $\mathrm{D}$ group) quantum yield ratios of poly(DGNG) (O) and BDGNBz $(\square)$ in HFIP/TMP (3:97) at $\lambda_{\mathrm{ex}}=260 \mathrm{~nm}$ and of poly(DNG) $(\triangle)$ in TMP at $\lambda_{\mathrm{ex}}=265 \mathrm{~nm}$. The quantum yields were determined from least-squares resolution of the fluorescence spectrum in the wavelength range of $320-360 \mathrm{~nm}$ into the contributions of monomer fluorescences of $\mathrm{D}$ and $\mathrm{N}$ groups.

lowering temperature. The ratio of poly(DNG) also decreases with lowering temperature, but the temperature dependence is weaker than that of the tripeptide. The origin of the exciplexes of poly(DGNG) is different from that in poly(DNG) and the model peptide, where thermal fluctuations of the excited D-N pair cause exciplex formation. The temperature independence in poly(DGNG) indicates that the exciplex formation does not require thermal activation. Presumably, the exciplex is formed at a site where some configurational defect may exist. A possible reason for the defect is the incorporation of a small amount of D-isomer in the polypeptide. Although no optical impurity has been detected in dmaPhe or in napAla by ${ }^{1} \mathrm{H}$ NMR spectroscopy measured in the presence of a chiral shift reagent, some racemization may be expected in the polymerization of the tetrapeptide activated ester. Aggregation is another possible reason for the exciplex formation. However, the fluorescence spectrum of a very 
dilute solution of poly(DGNG) ([naphthyl group] $=1 \times 10^{-6} \mathrm{M}$ was almost identical to that in Figure 5, indicating the absence of any interpolymer interaction.

\section{CONCLUSIONS}

The sequential polypeptide carrying $\mathrm{D}$ and $\mathrm{N}$ groups arranged periodically with the $\mathrm{D}-\mathrm{N}$ interchromophore distance of $12 \AA$ was synthesized. The arrangement consisted of onedimensional arrays of $\mathrm{D}$ and $\mathrm{N}$ groups along which energy migrates, without electron transfer-type interactions. The present study demonstrates that a polypeptide containing artificial aromatic amino acids in a specific order shows photophysical properties that can be predicted from the amino acid sequence by conformational calculations.

Acknowledgments. The financial support by a Grant-in-Aid for Scientific Research on Priority Areas, New Functionality Materials -Design, Preparation, and Control from the ministry of Education, Science, and Culture of Japan is acknowledged.

\section{REFERENCES AND NOTES}

1. M. Sisido, Makromol. Chem., Suppl., 14, 131 (1985).

2. M. Sisido, in "Photophysics of Polymers," C. E. Hoyle and J. M. Torkelson, Ed., ACS Symposium Series No. 358, 1987, Chapter 26.

3. M. Sisido, Y. Inai, and Y. Imanishi, Macromolecules, in press.

4. M. Sisido, S. Egusa, and Y. Imanishi, J. Am. Chem. Soc., 105, 1041 (1983).

5. M. Sisido, R. Tanaka, Y. Inai, and Y. Imanishi, $J$. Am. Chem. Soc., 111, 6790 (1989).
6. M. Sisido and Y. Imanishi, Macromolecules, 19, 2187 (1986).

7. F. A. Momany, R. F. McGuire, A. W. Burgess, and H. A. Scheraga, J. Phys. Chem., 79, 2361 (1975).

8. A sequential polypeptide having a repeating unit [dmaPhe-Ala-napAla-Glu(OBzl)] has been synthesized in a preliminary experiment of this study. The Ala unit was replaced by a $\mathrm{Glu}(\mathrm{OMe})$ unit in the later experiment described in the text, because of the limited solubility of the former polypeptide.

9. NAMOD molecular model drawing program was used to draw Figure 2. See, Y. Beppu, Computer \& Chem., 13, 101 (1989).

10. The $r_{0}$ values were calculated from the absorption and fluorescence spectra and the lifetimes of III and IV, measured in HFIP/TMP $(3: 97)$ mixed solvent, according to the Förster's equation. See, I. B. Berlman, "Energy Transfer Parameters of Aromatic Compounds," Academic Press, New York, N. Y., 1973.

11. The intrinsic lifetimes of $\mathbf{D}$ and $\mathbf{N}$ group was measured for IV and III in TMP. The fluorescence decay curves were well fitted to single-exponential decay functions.

12. For the energy transfer between two chromophores which are spatially fixed on a molecular frame, the orientation factor $\kappa^{2}=\left[e_{1} \cdot e_{2}-3\left(e_{1} \cdot r\right) \times\left(e_{2} \cdot r\right)\right]$ may deviate from the value for the averaged value for the random relative orientation (2/3). However, since the lowest excited states of $\mathrm{D}$ and $\mathrm{N}$ groups have a forbidden character, the directions of the fluorescent and the absorption transition moments are not clearly defined, but are distributed over the aromatic plane depending on the type of vibronic transitions. Under this circumstances, the use of the averaged orientation factor may be the best possible approximation. The qualitative discussion made in the text dose not change by a small change in the orientation factor.

13. Y. Inai, M. Sisido, and Y. Imanishi, submitted to $J$. Phys. Chem.

14. The quantum yield of the $\mathrm{N}^{*} \rightarrow \mathrm{D}$ energy transfer for $\mathrm{N}^{*}$ group is estimated from the intrinsic lifetime of $\mathrm{N}$ group and the rate constant of the energy transfer predicted. 